\title{
Comparative evaluation of anthropometric indices and ultrasonographically assessed abdominal fat thicknesses in young women with various total body fat mass
}

\author{
Elīza Švampe*, Līga Ozoliṇa-Moll \\ Faculty of Biology, University of Latvia, Academic Centre for Natural Sciences, Jelgavas 1, Rīga LV-1004, Latvia \\ ${ }^{\star}$ Corresponding author, E-mail: eliza.svampe@lu.lv
}

\begin{abstract}
The aim of this study was to evaluate a possible correlation between several ultrasonographic indices of abdominal adipose tissue and conventionally used anthropometric indices for evaluation of cardiometabolic diseases risk in a group of young, clinically healthy female subjects with various total body fat level. Fifty four women aged between 19 and 25 years participated in the study and were divided into three groups according to body mass index (BMI): underweight, normal weight and obese groups. The following anthropometric indices were obtained: BMI, waist circumference, hip circumference, waist-to-hip ratio, waist-to-height ratio, sagittal abdominal diameter, and body fat percentage. Preperitoneal, subcutaneous, mesenteric and intraabdominal fat thicknesses were measured by ultrasonography. All of the anthropometric indices used showed significant difference between each study group $(p<0.001)$. Our results suggest that in subjects with normal BMI, waist circumference, waist-to-height ratio and sagittal abdominal diameter are suitable parameters for visceral fat mass prediction. The female subjects with age 19 to 25 years with BMI $>30 \mathrm{~kg} \mathrm{~m}^{-2}$ had a metabolically healthy adiposity profile.
\end{abstract}

Key words: abdominal fat, anthropometry, obesity, ultrasound.

Abbreviations: AFI, abdominal wall fat index; BMI, body mass index; CMD, cardiometabolic diseases, IAT, intraabdominal fat thickness; MFT, mesenteric fat thickness; PFT $_{\max }$ maximal preperitoneal fat thickness; SAD, sagittal abdominal diameter; SFT $_{\text {min' }}$, minimal subcutaneous fat thickness; WC, waist circumference; WHO, World Health Organization; WHR, waist-to-hip ratio; WHtR, waist-to-height ratio.

\section{Introduction}

As the occurrence of cardiometabolic diseases (CMD) is increasing both in the world and in Latvia, the issue of early diagnostics of these diseases has become more and more important, as is the search for new morphometric, biochemical and physiological indicators, which would allow simple, but very accurate evaluation of the risk of cardiometabolic diseases.

One of the reasons promoting CMD is increased body fat level and obesity, and older, conventional indicators of cardiometabolic diseases risk such as body mass index and waist circumference, are based on weight and anthropometric measurements. New evidence of the adipose tissue endocrine function has promoted the need to find easily determined CMD risk indicators, which allow not only to evaluate the general volume of body fat level, but estimate the amount of the metabolically malignant fraction of adipose tissue.

In contrast to subcutaneous fat accumulation in the gluteal-femoral region, the accumulation of intraabdominal fat, especially visceral fat, is strongly associated with obesity-related complications. Recent evidence has shown several physiological and genetic differences between intraabdominal visceral-fat and peripheral subcutaneousfat. Such differences are also reflected in their dissimilar roles in the pathogenesis of obesity-related cardiometabolic diseases in both lean or obese individuals (Ibrahim 2010; Verrijken et al. 2011; Sironi et al. 2012). There are functional differences between visceral and the subcutaneous adipose tissue. Visceral adipose tissue and its resident macrophages produce more pro-inflammatory cytokines like tumour necrosis factor-alpha and interleukin-6, interleukin- $1 \beta$, C-reactive protein and less adiponectin (Lee et al. 2013; Spoto et al. 2014; Nam et al. 2015). These cytokine changes induce insulin resistance and play a major role in the pathogenesis of endothelial dysfunction (Farb et al. 2012; Higuchi et al. 2017).

In addition, the visceral fat level is strongly correlated with insulin resistance and type 2 diabetes (Matsuzawa 2008; $\mathrm{Xu}$ et al. 2012). The liver is directly exposed to increasing amounts of free fatty acids and pro-inflammatory cytokines released from visceral fat into the portal vein. This explains how visceral obesity may be particularly malignant in the pathogenesis of insulin resistance, type 2 diabetes and other cardiometabolic diseases (Item, Konrad 2012). 
Therefore, early estimation of cardiometabolic diseases risk requires indicators that would allow to identify the volume of metabolic malignant visceral fat in particular. The classical indicators are not always sufficiently informative for this purpose. Ultrasonographic evaluation of adipose tissue has been used in the last decade as an alternative method for anthropometric measurements for the purpose of estimating CMD risk. This method is sufficiently accurate, informative and cheap, compared to expensive computer tomography, which is accepted as the gold standard. Nevertheless, there is no common point of view regarding which of the ultrasonographically assessed abdominal fat fraction measurements could be used as a standard measurement for defining the metabolically malignant, visceral adiposity; therefore, standard values have not been defined yet.

The aim of this study was to evaluate possible correlation between several ultrasonographic indices of abdominal adipose tissue and conventionally used anthropometric indices for evaluation of cardiometabolic diseases risks in a group of young, clinically healthy female subjects with various total body fat level.

\section{Materials and methods}

\section{Subjects}

Fifty-four overall healthy Caucasian female volunteers aged between 19 and 25 years were enrolled in the current study and anthropometric parameters describing distribution of body fat mass and ultrasonographic indices of abdominal adipose tissue were determined. Exclusion criteria were: special training regimen otherwise than daily inevitable movements, metabolic disorders, and supplements for weight control. Consent was obtained from the participants, who were informed about the aim of the study and procedures to be carried out. Participants were divided in three groups according to their body mass index (BMI). $1^{\text {st }}$ group: underweight $\left(\mathrm{BMI}<18.5 \mathrm{~kg} \mathrm{~m}^{-2}, \mathrm{n}=13\right), 2^{\text {nd }}$ group: normal weight $\left(\mathrm{BMI}=18.5\right.$ to $\left.24.9 \mathrm{~kg} \mathrm{~m}^{-2}, \mathrm{n}=30\right)$ and $3^{\text {rd }}$ group: obese (BMI > $\left.30 \mathrm{~kg} \mathrm{~m}^{-2}, \mathrm{n}=11\right)$.

\section{Anthropometric measurements}

In order to calculate BMI, body height and weight were measured to the nearest $0.1 \mathrm{~cm}$ and $0.1 \mathrm{~kg}$, respectively, wearing lightweight clothing. Body mass index was calculated as weight in kilograms divided by height in meters squared $\left(\mathrm{kg} \mathrm{m}^{-2}\right)$ and rounded to the nearest tenth. Waist circumference (WC) was measured to the nearest $0.1 \mathrm{~cm}$ at the approximate midpoint between the lower margin of the last palpable rib and the top of the iliac crest. Hip circumference (HC) was measured to the nearest $0.1 \mathrm{~cm}$ at the widest portion of the buttocks. Both girths were measured with automatically-tightness adjusting tape. Waist-to-hip ratio (WHR) was calculated as waist circumference divided by hip circumference and rounded to the nearest hundredth. Waist-to-height ratio (WHtR) was calculated as waist circumference divided by height and rounded to the nearest hundredth. Sagittal abdominal diameter (SAD) was measured to the nearest $0.1 \mathrm{~cm}$ after a normal exhalation while the subjects were in a supine position on a firm examination table. The measurement was taken at the umbilicus level using a Holtain-Kahn Abdominal Caliper.

In order to evaluate body composition, seven skinfold thicknesses measurements were used to calculate body fat percentage (BF\%).

Skinfold measurements. Measurements of skinfold and subcutaneous fat tissue thicknesses were obtained from seven body sites using a Harpenden skinfold caliper (GIMA, Italy). All measurements were made on naked skin on the right side of the body (except for one participant whose dominant side of body motor asymmetry was the left). Skin and underlying subcutaneous adipose tissue was held between thumb and index finger of the left hand. The measurement was recorded 2 seconds after full pressure of the caliper was applied. Skinfold measurements were performed at the following body sites.

Biceps: midpoint between the acromion and olecranon protrusions on the front center line of the arm. The fold was parallel to the long axis of the arm. Triceps: midpoint between the acromion and olecranon protrusions on the posterior center line of the arm. The fold was parallel to the long axis of the arm. Abdomen: a vertical pinch was made $5 \mathrm{~cm}$ lateral to the umbilicus. Suprailiac: just above the intersection of the anterior axillary line with the anterior superior iliac spine. Subscapular: $2 \mathrm{~cm}$ below the bottom end of the scapula. Thigh: midpoint of an imaginary line drawn between the upper edge of the patella and midpoint of inguinal ligament on the front of the thigh. Calf: medial side of the thickest part of the calf.

Body fat percentage was calculated using three equations (Jackson et al. 1980; Durnin, Womersley 1974; Yuhasz 1974) and mean value was calculated and used for further analysis.

All anthropometric measurements were repeated three times and mean values were calculated and used for further data analysis.

\section{Ultrasonographic measurement of abdominal adipose tissue}

Abdominal fat thicknesses were measured using a portable high-resolution ultrasound device (Logiq, GE Healthcare, USA). For measurements two ultrasonic transducers were used: linear transducer (12L - RS) and curvilinear transducer (4C - RS). Measurement was performed at least 5 hours after the last meal at the end of a normal exhalation in the supine position. For each participant, a total of four measurements were made as follows: (a) maximal preperitoneal $\left(\mathrm{PFT}_{\max }\right)$ and (b) minimal subcutaneous fat thicknesses $\left(\mathrm{SFT}_{\min }\right)$ were measured in the midline between 
xiphoid process and umbilicus (Fig. 1); (c) intraabdominal fat thickness (IAT) was measured $5 \mathrm{~cm}$ above umbilicus as the distance between the internal face of the musculus rectus abdominis and the anterior wall of the aorta along the line alba (Fig. 2); (d) mesenteric fat thickness (MFT) was measured as the distance between mesenteric leaves, which appeared as tubular structures with linear hyperechoic peritoneal layers (Fig. 3).

At least six mesenteric fat measurements were obtained and the mean value of three thickest measurements was taken for analysis. Abdominal wall fat index (AFI) was calculated as preperitoneal fat thickness divided by minimal subcutaneous fat thickness.

All measurements were obtained by the same investigator and repeated 3 times and mean values were calculated and used for further data analysis.

\section{Statistical analysis}

Statistical analyses were performed by using SigmaPlot (Systat Software, Inc). Data for each participant group

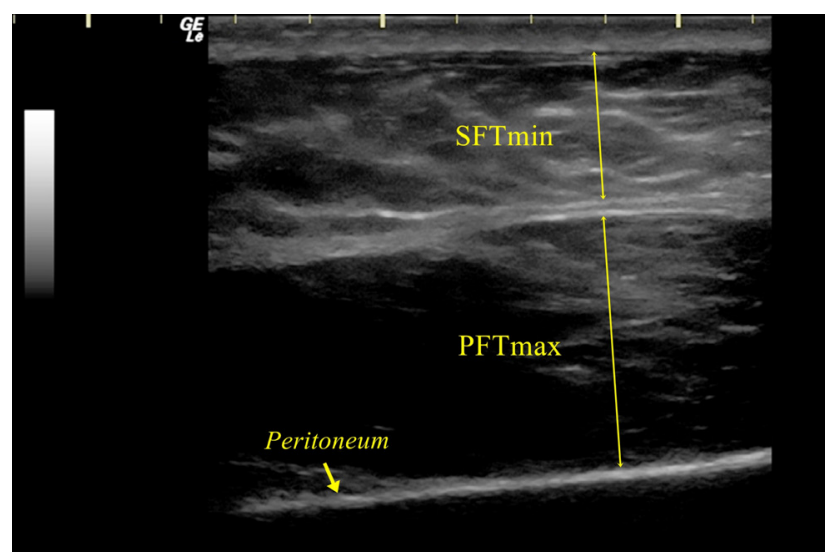

Fig. 1. Ultrasonographically assessed preperitoneal and subcutaneous fat thicknesses. $\mathrm{PFT}_{\max }$, maximal preperitoneal fat thickness; $\mathrm{SFT}_{\text {min }}$, minimal subcutaneous fat thickness.

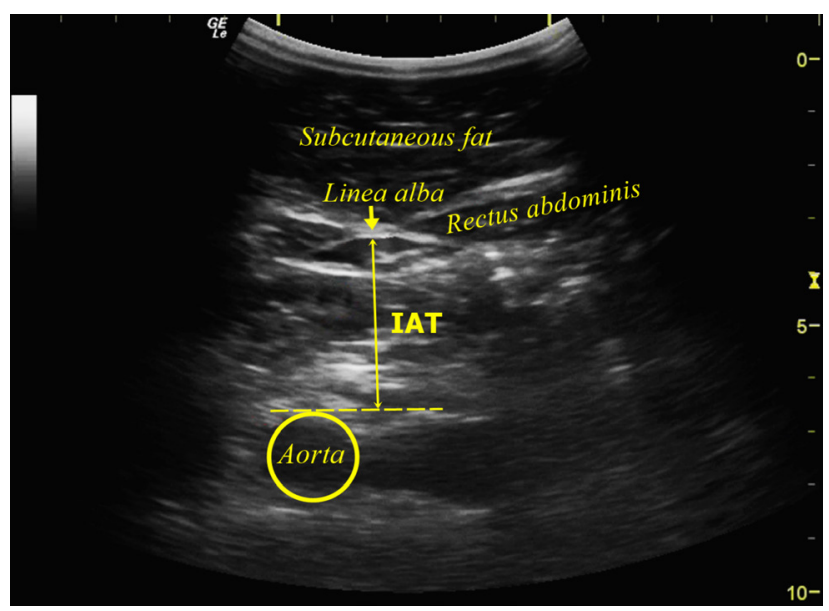

Fig. 2. Ultrasonographically assessed intraabodminal fat thickness. IAT, intraabdominal fat thickness. were analyzed separately. The Shapiro-Wilk test was used to test normality. Parametric tests were applied when variables were distributed normally and non-parametric tests in other casesy. Relationships between continuous variables were tested by Pearson's correlation coefficients. Comparison between groups was done with an unpaired t-test. Comparison of variables lacking normal distribution was performed by using the Kruskal-Wallis Analysis of Ranks. A $p$ value $<0.05$ was considered as statistically significant.

\section{Results}

The main characteristics of the study participants are presented in Table 1 . The mean age \pm SD of volunteers in underweight group, normal weight group and obese group was $20.69 \pm 1.18,22.13 \pm 2.01$ and $23.27 \pm 3.00$ years, respectively.

\section{Anthropometry}

Participants were divided into three groups according to their BMI. The group cut-off values were based on WHO recommendations (WHO 2008). Mean BMI was 17.17 $\pm 0.85 \mathrm{~kg} \mathrm{~m}^{-2}$ in underweight group; $21.49 \pm 1.43 \mathrm{~kg} \mathrm{~m}^{-2}$ in normal weight group and $35.82 \pm 5.98 \mathrm{~kg} \mathrm{~m}^{-2}$ in obese group. Differences in BMI were statistically significant $(p<$ 0.001 ) between the three groups (Table 1 ).

WC, WHR, WHtR and SAD are anthropometric parameters commonly used to describe adipose tissue distribution (de Souza, de Oliveira 2013; Goh et al. 2014; $\mathrm{Bi}$ et al. 2016). There was statistically significant difference for all these parameters between each study group (Table 2 ). Waist circumference in underweight and normal weight groups was in the healthy range $(61$ to $77 \mathrm{~cm})$, i.e., lower than the value of $80 \mathrm{~cm}$ given in a WHO report (WHO 1997). All participants in the obese group had higher WC (87 $\mathrm{cm}$ and 128) than the $80 \mathrm{~cm}$ cut-off value, suggesting a higher risk for cardiometabolic diseases.

WHR, WHtR and SAD in the obese group were also higher than recommended cut-off values for women

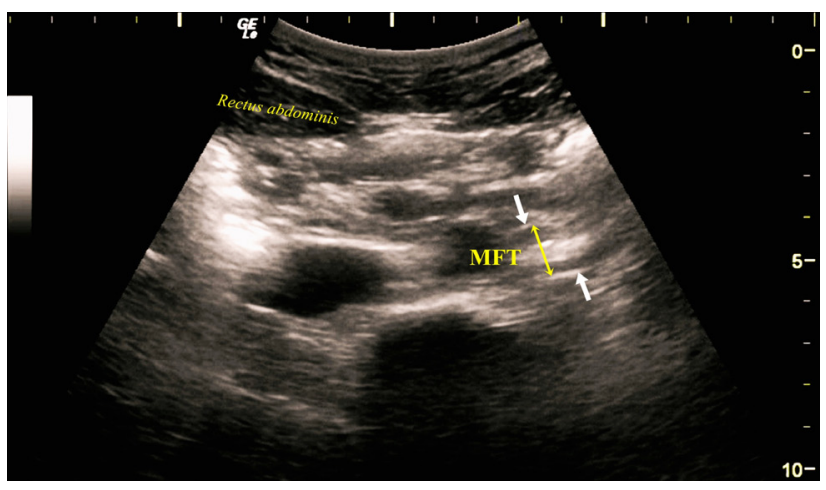

Fig. 3. Ultrasonographically assessed mesenteric fat thickness. White arrows indicate mesenteric leaves. MFT, mesenteric fat thickness. 
Table 1. Characteristic parameters of investigated persons in each group. $\dagger$, statistically significant difference between underweight group and indicated group; $\neq$, statistically significant difference between normal weight group and indicated group; $\phi$, statistically significant difference between obese group and indicated group. BMI, body mass index; BF\%, body fat percentage; WC, waist circumference; HC, hip circumference; WHR, waist-to-hip ratio; WHtR, waist-to-height ratio; SAD, sagittal abdominal diameter; PFT ${ }_{\text {max }}$, maximal preperitoneal fat thickness; $\mathrm{SFT}_{\text {min }}$, minimal subcutaneous fat thickness; AFI, abdominal wall fat index; MFT, mesenteric fat thickness; IAT, intraabdominal fat thickness

\begin{tabular}{|c|c|c|c|c|c|c|}
\hline \multirow[t]{2}{*}{ Parameters } & \multicolumn{2}{|c|}{ Underweight group $(n=13)$} & \multicolumn{2}{|c|}{ Normal weight group $(n=30)$} & \multicolumn{2}{|c|}{ Obese group $(n=11)$} \\
\hline & Mean & SD & Mean & SD & Mean & SD \\
\hline \multicolumn{7}{|l|}{ General } \\
\hline Age (years) & $20.69 \ddagger \phi$ & 1.18 & $22.13 \dagger$ & 2.01 & $23.27 \dagger$ & 3.00 \\
\hline Height (m) & 1.70 & 0.07 & 1.68 & 0.05 & 1.69 & 0.08 \\
\hline Weight (kg) & $49.74 \ddagger \phi$ & 4.61 & $60.66+\phi$ & 5.62 & $101.85 \dagger \ddagger$ & 18.91 \\
\hline BMI $\left(\mathrm{kg} \mathrm{m}^{-2}\right)$ & $17.17 \ddagger \phi$ & 0.85 & $21.49+\phi$ & 1.43 & $35.82 \dagger \ddagger$ & 5.98 \\
\hline \multicolumn{7}{|l|}{ Anthropometry } \\
\hline $\mathrm{BF}(\%)$ & $19.11 \ddagger \phi$ & 3.76 & $24.74 \dagger \phi$ & 3.34 & $39.13 \dagger \neq$ & 2.90 \\
\hline $\mathrm{WC}(\mathrm{cm})$ & $64.23 \ddagger \phi$ & 4.13 & $72.43+\phi$ & 2.98 & $105.42 \dagger \ddagger$ & 11.76 \\
\hline $\mathrm{HC}(\mathrm{cm})$ & $88.91 \ddagger \phi$ & 3.02 & $95.97 \dagger \phi$ & 3.79 & $111.95 \dagger \ddagger$ & 12.53 \\
\hline WHR & $0.74 \ddagger \phi$ & 0.04 & $0.76 \dagger \phi$ & 0.03 & $0.89 \dagger \ddagger$ & 0.04 \\
\hline WHtR & $0.39 \ddagger \phi$ & 0.02 & $0.42 \dagger \phi$ & 0.02 & $0.64 \dagger \ddagger$ & 0.07 \\
\hline $\mathrm{SAD}(\mathrm{cm})$ & $13.93 \neq \phi$ & 1.45 & $16.02 \dagger \phi$ & 1.28 & $23.16 \dagger \ddagger$ & 7.21 \\
\hline \multicolumn{7}{|c|}{ Abdominal fat measurements } \\
\hline $\operatorname{PFTmax}(\mathrm{cm})$ & $1.00 \phi$ & 0.30 & $1.04 \phi$ & 0.46 & $2.40 \dagger \ddagger$ & 0.54 \\
\hline SFTmin $(\mathrm{cm})$ & $0.61 \ddagger \phi$ & 0.16 & $1.22 \dagger \phi$ & 0.52 & $3.15 \dagger \ddagger$ & 0.87 \\
\hline AFI & $1.78 \ddagger \phi$ & 0.79 & $0.99 \dagger$ & 0.55 & $0.81 \dagger \ddagger$ & 0.24 \\
\hline $\operatorname{MFT}(\mathrm{cm})$ & $0.75 \phi$ & 0.10 & $0.88 \phi$ & 0.22 & $1.92 \dagger$ & 0.44 \\
\hline $\operatorname{IAT}(\mathrm{cm})$ & $2.52 \phi$ & 0.47 & $2.77 \phi$ & 0.83 & $5.21 \dagger \ddagger$ & 1.69 \\
\hline
\end{tabular}

Table 2. Statistical significance of difference between each study group for anthropometric measurements and ultrasonographic abdominal fat thicknesses. BMI, body mass index; BF\%, body fat percentage; WC, waist circumference; HC, hip circumference; WHR, waist-to-hip ratio; WHtR, waist-to-height ratio; $\mathrm{SAD}$, sagittal abdominal diameter; $\mathrm{PFT}_{\max }$, maximal preperitoneal fat thickness; $\mathrm{SFT}_{\text {min' }}$ ' minimal subcutaneous fat thickness; AFI, abdominal wall fat index; MFT, mesenteric fat thickness; IAT, intraabdominal fat thickness

\begin{tabular}{|c|c|c|c|}
\hline Parameters & $\begin{array}{l}\text { Statistical significance } \\
\text { of difference between } \\
\text { underweight group and } \\
\text { normal weight groups }\end{array}$ & $\begin{array}{l}\text { Statistical significance of } \\
\text { difference between normal } \\
\text { weight and obese groups }\end{array}$ & $\begin{array}{c}\text { Statistical significance } \\
\text { of difference between } \\
\text { underweight and obese groups }\end{array}$ \\
\hline \multicolumn{4}{|c|}{ Anthropometry } \\
\hline Height (m) & 0.449 & 0.899 & 0.637 \\
\hline Weight (kg) & $<0.001$ & $<0.001$ & $<0.001$ \\
\hline $\mathrm{BMI}\left(\mathrm{kg} \mathrm{m}^{-2}\right)$ & $<0.001$ & $<0.001$ & $<0.001$ \\
\hline $\mathrm{BF}(\%)$ & $<0.001$ & $<0.001$ & $<0.001$ \\
\hline $\mathrm{WC}(\mathrm{cm})$ & $<0.001$ & $<0.001$ & $<0.001$ \\
\hline WHR & $<0.001$ & $<0.001$ & $<0.001$ \\
\hline WHtR & $<0.001$ & $<0.001$ & $<0.001$ \\
\hline $\mathrm{SAD}(\mathrm{cm})$ & $<0.001$ & $<0.001$ & $<0.001$ \\
\hline \multicolumn{4}{|c|}{ Abdominal fat thicknesses } \\
\hline $\mathrm{PFT}_{\max }(\mathrm{cm})$ & 0.617 & $<0.001$ & $<0.001$ \\
\hline $\mathrm{SFT}_{\text {min }}(\mathrm{cm})$ & $<0.001$ & $<0.001$ & $<0.001$ \\
\hline AFI & $<0.001$ & 0.486 & $<0.001$ \\
\hline $\operatorname{MFT}(\mathrm{cm})$ & 0.389 & $<0.001$ & $<0.001$ \\
\hline $\operatorname{IAT}(\mathrm{cm})$ & 0.298 & $<0.001$ & $<0.001$ \\
\hline
\end{tabular}


Table 3. Pearson correlation coefficients between abdominal fat thicknesses and anthropometric parameters. ${ }^{*}, p<0.05$; ${ }^{* *}, p<0.01$; ${ }^{* * *}, p<0.001$. WC, waist circumference; HC, hip circumference; WHR, waist-to-hip ratio; WHtR, waist-to-height ratio; SAD, sagittal abdominal diameter; $\mathrm{PFT}_{\max }$, maximal preperitoneal fat thickness; $\mathrm{SFT}_{\min }$, minimal subcutaneous fat thickness; AFI, abdominal wall fat index; MFT, mesenteric fat thickness; IAT, intraabdominal fat thickness

\begin{tabular}{|c|c|c|c|c|c|c|}
\hline \multirow{2}{*}{\multicolumn{2}{|c|}{ Abdominal fat thickness }} & \multicolumn{5}{|c|}{ Anthropometric measurements } \\
\hline & & r, BMI & r, WC & r, WHR & r, WHtR & r, SAD \\
\hline \multirow{5}{*}{$\begin{array}{l}\text { Underweight group } \\
(\mathrm{n}=13)\end{array}$} & $\mathrm{PFT}_{\max }$ & 0.04 & 0.31 & 0.28 & 0.28 & 0.32 \\
\hline & $\mathrm{SFT}_{\min }$ & 0.21 & 0.15 & 0.07 & -0.13 & -0.07 \\
\hline & AFI & -0.07 & 0.20 & 0.23 & 0.28 & 0.34 \\
\hline & MFT & 0.27 & 0.49 & $0.54^{*}$ & 0.52 & 0.19 \\
\hline & IAT & 0.31 & 0.38 & 0.38 & 0.43 & 0.37 \\
\hline \multirow{5}{*}{$\begin{array}{l}\text { Normal weight group } \\
(\mathrm{n}=30)\end{array}$} & $\mathrm{PFT}_{\max }$ & 0.03 & 0.23 & $0.48^{*}$ & 0.19 & 0.20 \\
\hline & $\mathrm{SFT}_{\min }$ & 0.17 & $0.50^{\star *}$ & 0.34 & $0.53^{\star *}$ & $0.61^{\star * *}$ \\
\hline & AFI & -0.19 & -0.15 & 0.11 & -0.19 & -0.28 \\
\hline & MFT & $0.52^{*}$ & $0.62^{* * *}$ & 0.14 & $0.47^{\star *}$ & $0.49^{* *}$ \\
\hline & IAT & 0.15 & 0.18 & 0.10 & -0.05 & $0.39^{*}$ \\
\hline \multicolumn{7}{|l|}{ Obese group } \\
\hline \multirow[t]{5}{*}{$(\mathrm{n}=11)$} & $\mathrm{PFT}_{\max }$ & 0.12 & 0.43 & 0.49 & 0.40 & -0.18 \\
\hline & $\mathrm{SFT}_{\min }$ & 0.33 & 0.48 & 0.11 & 0.40 & 0.47 \\
\hline & AFI & -0.23 & -0.11 & 0.32 & -0.08 & -0.13 \\
\hline & MFT & 0.38 & 0.44 & 0.14 & 0.31 & 0.30 \\
\hline & IAT & 0.58 & 0.38 & 0.02 & 0.36 & $0.71^{*}$ \\
\hline
\end{tabular}

(>0.85, > 0.5 and > $20.1 \mathrm{~cm}$, respectively) (WHO 2008; Browning et al. 2010; Duarte et al. 2010). These results suggest that participants in the obese group have central adiposity, which is associated with metabolic complications (Després et al. 2008).

Table 3 shows distribution of $\mathrm{BF} \%$ classes in each study group. In the underweight group 10 of 13 participants corresponded to decreased body fat mass (BF\% classes I and II), and three persons had BF\% that showed normal body fat mass (BF\% class III). In the normal weight group, all BF\% classes were represented: 10 participants corresponded to normal body fat mass, six participants to decreased body fat mass, 12 participants to slightly increased fat mass (BF\% class IV) and two participants corresponded to extremely increased fat mass ( $\mathrm{BF} \%$ class $\mathrm{V})$. The $\mathrm{BF} \%$ range in the normal weight group was between 18.3 and $30.9 \%$ body fat. All participants in obese group had $\mathrm{BF} \%$ that corresponded to extremely increased fat mass.

\section{Abdominal fat thicknesses assessed by ultrasonography}

Five abdominal fat indices were determined by using ultrasonography method (Table 1). There was a significant difference between underweight and obese groups for all parameters $(p<0.001)$. A statistically significant difference was not found between underweight and normal weight groups for PFTmax, MFT and IAT and between the normal weight group and obese group for AFI.

\section{Correlative analysis between abdominal fat thicknesses and anthropometry}

Correlative analysis was performed to evaluate relationship between anthropometric parameters that describe adipose tissue distribution and ultrasonographic measurements of abdominal fat thicknesses. Table 4 shows Pearson correlation coefficients $r$ between parameters in each study group. In the underweight group, the only significant correlation was between MFT and WHR $(r=0.54, p=0.046)$.

Table 4. Distribution of investigated persons by body fat classes in each study group. ${ }^{\star}$ Adapted from Gima Plicometro caliper manual. $\mathrm{BF}(\%)$, body fat percentage

\begin{tabular}{|c|c|c|c|c|c|c|}
\hline & \multicolumn{2}{|c|}{ Underweight group $(n=13)$} & \multicolumn{2}{|c|}{ Normal weight group $(n=30)$} & \multicolumn{2}{|c|}{ Obese group $(\mathrm{n}=11)$} \\
\hline & Mean & SD & Mean & SD & Mean & SD \\
\hline $\mathrm{BF}(\%)$ & 19.11 & 3.76 & 24.74 & 3.34 & 39.13 & 2.90 \\
\hline $\begin{array}{l}\text { Representation of BF (\%) } \\
\text { classes in study groups }\end{array}$ & $\begin{array}{r}\text { I class }(\mathrm{n}=5) \\
\text { class }\end{array}$ & $\begin{array}{l}\text { ass }(\mathrm{n}=5) \text {; III } \\
=3)\end{array}$ & $\begin{array}{r}\text { I class }(\mathrm{n}= \\
\text { class }(\mathrm{n}=1 \\
\mathrm{V}\end{array}$ & $\begin{array}{l}(\mathrm{n}=3) ; \text { III } \\
\text { s }(\mathrm{n}=12) \text {; } \\
\text { 2) }\end{array}$ & $\mathrm{V} \mathrm{cl}$ & $h=11)$ \\
\hline $\begin{array}{l}\text { Recommended BF } \quad \text { (\%) } \\
\text { classes* }^{*}\end{array}$ & $\begin{array}{c}\text { I class }(\%)< \\
19.0\end{array}$ & $\begin{array}{l}\text { II class }(\%) \\
19.1-22.0\end{array}$ & III cla & -25.0 & $\begin{array}{l}\text { IV class }(\%) \\
25.1-30.0\end{array}$ & $\begin{array}{c}\mathrm{V} \text { class }(\%)> \\
30.0\end{array}$ \\
\hline
\end{tabular}


In the normal weight group MFT showed more and higher positive correlations with anthropometric measures than $\mathrm{PFT}_{\text {max }}$ or IAT. MFT correlated strongly with BMI, WC, WHtR and SAD $(r=0.52, p=0.02 ; r=0.62, p=0.0002 ; r$ $=0.47, p=0.009 ; r=0.49, p=0.0098$, respectively). Strong positive correlation was found also between $\mathrm{SFT}_{\min }$ and WC, and WHtR and SAD $(r=0.50, p=0.0045 ; r=0.53, p$ $=0.002 ; r=0.61, p=0.00064$, respectively). No significant relationship was found between AFI and anthropometry for participants with normal BMI.

In the obese group the only strong relationship was between IAT and SAD $(r=0.71, p=0.022)$.

\section{Discussion}

The aim of the present study was to evaluate if anthropometric parameters are correlated with and ultrasonographical abdominal fat parameters in young women with various body fat mass and to evaluate probability for early cardiometabolic risk prediction.

Ultrasonography method has already proved its validity for abdominal adiposity assessment, by strong correlations $(r=0.81$ to $0.98, p<0.001)$ with "gold standard" methods (Tornaghi et al. 1994; Stolk et al. 2001; Bazzocchi et al. 2011). However, to obtain accurate measurements of different abdominal fat layers, special training is obligatory, and the costs of ultrasonography are higher compared to anthropometry. Our present study suggests that in young women, SAD is a better predictor of visceral fat than other anthropometric parameters, such as WC, WHR and WHtR and showed significant and strong correlation with abdominal fat thickness assessed by ultrasonography ( $r$ varied from 0.39 to $0.71, p<0.05$ ) (Table 4 ).

$\mathrm{BMI}$ is the most common parameter for classification of overweightness and obesity, but its accuracy to predict body fat is better if used in large population studies. Several studies have explored the limitations of BMI (Rush et al. 2009; Rahman, Berenson 2010; Chiu et al. 2011). Although subjects of the current study had a similar daily activity level, the results showed a great variation of body fat percentage $(\mathrm{BF} \%=18.3$ to $30.9 \%)$ in a group with normal body weight according to BMI (BMI $=18.5$ to $\left.24.9 \mathrm{~kg} \mathrm{~m}^{-2}\right)$. These results suggest that BMI cannot distinguish between lean body mass and fat mass. Ode with his colleagues tested BMI as a predictor of $\mathrm{BF} \%$ in college students who were athletes or nonathletes. They concluded that there is necessity for different BMI classification systems (Ode et al. 2007).

In scientific literature, there are controversial data about BMI as a predictor of regional adipose tissue depots. Some studies have shown extremely strong relationship between BMI and visceral adipose tissue $(r=0.60$ to $0.82, p<0.01)$ (Jansen et al. 2002; Bouchard 2007). In our present study, we found only one significant correlation between BMI and MFT in the normal weight group $(r=0.52, p=0.02)$ (Table 4). Considering the limitations of BMI, it should be used with caution for body composition assessment.

Clinical assessment of abdominal fat depots is important because central obesity is associated with increased proinflammatory cytokine production, decreased insulin sensitivity, development of type 2 diabetes, atherosclerosis and its consequences (Wajchenberg 2000).

In recent years ultrasonography has been widely used to assess regional adiposity. In our study, we used four abdominal fat parameters that describe abdominal adiposity. AFI is calculated by dividing $\mathrm{PFT}_{\max }$ with $\mathrm{SFT}_{\text {min, }}$ and values greater than 1 are associated with increased visceral adipose tissue accumulation (Vlachos et al. 2007). In our study, the highest AFI was observed in the underweight group (AFI $=1.78$ ) (Table 1). This result should not be interpreted as an indicator of unhealthy adiposity phenotype, as it is due to the small subcutaneous fat layer rather than increased preperitoneal fat depots. This suggests that AFI should be not recommended for early prediction of central adiposity type (subcutaneous versus visceral) in subjects with low BMI.

AFI in the obese study group was significantly lower than in the underweight group (AFI $=0.81$ ), with values characterizing of the metabolically healthy adiposity type. We can speculate that in the population of young women, increase of total fat mass was accompanied by a proportional increase between different abdominal fat depots - subcutaneous and visceral.

$\mathrm{PFT}_{\text {max }}$ was significantly higher in the obese group than in the other groups, but the difference was not significant between underweight and normal weight groups. It is not clear if preperitoneal fat depots are an accurate indicator of visceral fat. Although preperitoneal fat metabolically is more similar to visceral fat than subcutaneous fat, $\mathrm{PFT}_{\max }$ was shown to have the weakest correlation with cardiometabolic risk factors like cholesterol and highdensity and low-density lipoproteins etc. (Liu et al. 2003).

MFT and IAT were also significantly higher in obese group compared with the other groups, but the difference was not significant between underweight and normal weight groups. MFT might be a more accurate measure of visceral fat compared to other parameters because it might eliminate methodological errors originating from imprecise measurement location. MFT has been shown to have strong correlation with visceral fat mass assessed by magnetic resonance imaging or computed tomography (Liu et al. 2003; Liu et al. 2006). IAT had the highest amount of deviation compared to other abdominal fat thicknesses in all study groups. We can speculate that the visceral fat amount is not dependent on total body fat mass. Moreover, in the past decade the concept of obesity has been changing and a new type of obesity has been proposed - normal weight obesity, which is characterized by a normal BMI but shows all the cardiometabolic complications associated with obesity (Oliveros et al. 2014).

We conclude that in the young women population with 
increased total body fat mass, distribution of abdominal adipose tissue is associated with metabolically healthy body fat accumulation, i.e., predominantly subcutaneous.

We found the most significant correlation between anthropometric indices and abdominal fat thicknesses in normal weight group (Table 4). We can speculate that in persons with normal BMI anthropometric indices such as WC, WHtR and SAD, can be used to predict visceral fat.

\section{References}

Bazzocchi A., Filonzi G., Ponti F., Sassi C., Salizzoni E., Battista G., Canini R. 2011. Accuracy, reproducibility and repeatability of ultrasonography in the assessment of abdominal adiposity. Acad. Radiol. 18: 1133-1143.

Bi X., Tey S.L., Leong C., Quek R., Loo Y.T., Henry C.J. 2016. Correlation of adiposity indices with cardiovascular disease risk factors in healthy adults of Singapore: a cross-sectional study. BMC Obes. 3: 33-40.

Boouchard C. 2007. BMI, fat mass, abdominal adiposity and visceral fat: where is the "beef"? Int. J. Obesity 31: 1552-1553.

Browning L.M., Hsieh S.D., Ashwell M. 2010. A systematic review of waist-to-height ratio as a screening tool for the prediction of cardiovascular disease and diabetes: 0.5 could be a suitable global boundary value. Nutr. Res. Rev. 23: 247-269.

Chiu M., Austin P.C., Manuel D.G., Shah B.R., Tu J.V. 2011. Deriving ethnic-specific BMI cutoff points for assessing diabetes risk. Diabetes Care 34: 1741-1748.

De Souza N.C., de Oliveira E.P. 2013. Sagittal abdominal diameter shows better correlation with cardiovascular risk factors than waist circumference and BMI. J. Diabetes Metab. Disord. 12: 41-46.

Després J.P., Lemieux I., Bergeron J., Pibarot P., Mathieu P., Larose E., Rodés-Cabau J., Bertrand O.F, Poirier P. 2008. Abdominal obesity and the metabolic syndrome: contribution to global cardiometabolic risk. Arterioscl. Thromb. Vasc. 28: 1039-1049.

Durnin J.V.G.A., Womersley J. 1974. Body fat assessed from total body density and its estimation from skinfold thickness: measurements on 481 men and women aged from 16 to 72 years. Br. J. Nutr. 32: 77-97.

Farb M.G., Ganley-Leal L., Mott M., Liang Y., Ercan B., Widlansky M.E., Bigornia S.J., Fiscale A.J., Apovian C.M., Carmine B., Hess D.T., Vita J.A., Gokce N. 2012. Arteriolar function in visceral adipose tissue is impaired in human obesity. Arterioscl. Thromb. Vasc. 32: 467-473.

Goh L.G.H., Dhaliwal S.S., Welborn T.A., Lee A.H., Della P.R. 2014. Anthropometric measurements of general and central obesity and the prediction of cardiovascular disease risk in women: a cross-sectional study. Brit. Med. J. Open 4: e004138.

Hamdy O., Porramatikul S., Al-Ozairi E. 2006. Metabolic obesity: the paradox between visceral and subcutaneous fat. Curr. Diabetes Rev. 2: 367-373.

Higuchi S., Kabeya Y., Kato K. 2017. Visceral-to-subcutaneous fat ratio is independently related to small and large cerebrovascular lesions even in healthy subjects. Atherosclerosis 259: 41-45.

Ibrahim M.M. 2010. Subcutaneous and visceral adipose tissue: structural and functional differences. Obes. Rev. 11: 11-8.

Item F., Konrad D. 2012. Visceral fat and metabolic inflammation - the portal theory revisited. Obes. Rev. 13: 30-39.

Jackson A.S., Pollock M.L., Ward A. 1980. Generalized equations for predicting body density of women. Med. Sci. Sport. Exer.
12: 175-181.

Jansen I., Heymsfield S. B., Allison D.B., Kotler D.P., Ross R. 2002. Body mass index and waist circumference independently contribute to the prediction of nonabdominal, abdominal subcutaneous, and visceral fat. Am. J. Clin. Nutr. 75: 683-688.

Lee M.J., Wu Y., Fried S.K. 2013. Adipose tissue heterogeneity: Implications of depot differences in adipose tissue for obesity complications. Mol. Aspects Med. 34: 1-11.

Li X., Katashima M., Yasumasu T., Li K.J. 2012. Visceral fat area, waist circumference and metabolic risk factors in abdominally obese Chinese adults. Biomed. Environ. Sci. 25: 141-148.

Liu K.H., Chan Y.L., Chan J.C., Chan W.B., Kong W.L. 2006. Mesenteric fat thickness as an independent determinant of fatty liver. Int. J. Obesity 30: 787-793.

Liu K.H., Chan Y.L., Chan W.B., Kong W.L., Kong M.O., Chan J.C.N. 2003. Sonographic measurement of mesenteric fat thickness is a good correlate with cardiovascular risk factors: comparison with subcutaneous and preperitoneal fat thickness, magnetic resonance imaging and anthropometric indexes. Int. J. Obesity 27: $1267-1273$.

Matsuzawa Y. 2008. The role of fat topology in the risk of disease. Int. J. Obesity 32: 83-92.

Nam S.Y., Choi I.J., Ryu K.H., Park B.J., Kim Y.W., Kim H.B., Kim J.S. 2015. The effect of abdominal visceral fat, circulating inflammatory cytokines, and leptin levels on reflux esophagitis. J. Neurogastroenterol. 21: 247-254.

Ode J.J., Pivarnik J.M., Reeves M.J., Knous J.L. 2007. Body mass index as a predictor of percent fat in college athletes and nonathletes. Med. Sci. Sport. Exer. 39: 403-409.

Oliveros E., Somers V.K., Sochor O., Goel K., Lopez-Jimenez F. 2014. The concept of normal weight obesity. Prog. Cardiovasc. Dis. 56: 426-433.

Duarte Pimentel G., Portero-McLellan K.C., Maestá N., Corrente J.E., Burini R.C. 2010. Accuracy of sagittal abdominal diameter as predictor of abdominal fat among Brazilian adults: a comparation with waist circumference. Nutr. Hosp. 25: 656-661.

Rahman M., Berenson A.B. 2010. Accuracy of current body mass index obesity classification for white, black and Hispanic reproductive-age women. Obstet. Gynecol. 115: 982-988.

Rush E.C., Freitas I., Plank L.D. 2009. Body size, body composition and fat distribution: comparative analysis of European, Maori, Pasific Island and Asian Indian adults. Br. J. Nutr. 102: 632634.

Sironi A.M., Petz R., De Marchi D., Buzzigoli E., Ciociaro D., Positano V., Lombardi M., Ferrannini E., Gastaldelli A. 2012. Impact of increased visceral and cardiac fat on cardiometabolic risk and disease. Diabetic Med. 29: 622-627.

Spoto B., Di Betta E., Mattace-Raso F., Sijbrands E., Vilardi A., Parlongo RM.., Pizzini P., Pisano A., Vermi W., Testa A., Cutrupi S., D’Arrigo G., Lonardi S., Tripepi G., Cancarini G., Zoccali C. 2014. Pro- and anti-inflammatory cytokine gene expression in subcutaneous and visceral fat in severe obesity. Nutr. Metab. Cardiovas. 24: 1137-1143.

Stolk R.P., Wink O., Zelissen P.M.J., Meijer R., van Gils A.P.G., Grobbee D.E. 2001. Validity and reproducibility of ultrasonography for the measurement of intra-abdominal adipose tissue. Int. J. Obesity 25: 1346-1351.

Tornaghi G., Raiteri R., Pozzato C., Rispoli A., Bramani M., Cipolat M., Craveri A. 1994. Anthropometric or ultrasonic measurements in assessment of visceral fat? A comparative study. Int. J. Obes. Relat. Metab. Disord. 18: 771-775. 
Verrijken A., Francque S., Van Gaal L. 2011. The role of visceral adipose tissue in the pathogenesis of non-alcoholic fatty liver disease. Eur. J. Endocrinol. 7: 96-103.

Vlachos I.S., Hatziioannou A., Perelas A., Perrea D.N. 2007. Sonographic assessment of regional adiposity. Am. J. Roentgenol. 189: 1545-1553.

Wajchenberg B.L. 2000. Subcutaneous and visceral adipose tissue: their relation to the metabolic syndrome. Endocr. Rev. 21: 697-738.

World Health Organization 1997. Preventing and managing the global epidemic: report of a WHO consultation on obesity, Geneva.

World Health Organization 2008. Waist circumference and waisthip ratio. Report of a WHO expert consultation, Geneva.

Yuhasz M.S. 1974. Physical Fitness Manual. London, University of Western Ontario, 204 pp.

Xu L., Mitsushiro K., Takeshi Y., Ji L.K. 2012. Visceral fat area, waist circumference and metabolic risk factors in abdominally obese Chinese adults. Biomed. Environ. Sci. 25: 141-148. 